\title{
Foramen Magnum Meningioma: A Rare Case Report
}

\author{
Haradhan Deb Nath* \\ Kanak Kanti Barua \\ Shahnewaj Bari \\ Hafizul Amin
}

Department of Neurosurgery

Bangabandhu Sheikh Mujib Medical University Dhaka, Bangladesh.

\section{*Correspondence to:}

\footnotetext{
Dr. Haradhan Deb Nath

Associate Professor

Department of Neurosurgery

Bangabandhu Sheikh Mujib Medical University

Dhaka, Bangladesh

Mobile: +8801711354120

E-mail: dr.haradhan@yahoo.com

$w w w . c m o s h m c j . \circ r g$
}

\begin{abstract}
Background: Foramen magnum meningiomas are challenging tumors, requiring special considerations because of the vicinity of the medulla oblongata, the lower cranial nerves, and the vertebral artery. After detailing the relevant anatomy of the foramen magnum area, we will explain our classification system based on the compartment of development, the dural insertion, and the relation to the vertebral artery. Method: A 35 years age lady with foramen magnum meningioma was operated at the Department of Neurosurgery, Bangabandhu Sheikh Mujib Medical University 6 months back. A case report was taken before surgery and 6 month follow up was done after operation. Conclusion : As foramen magnum meningioma is very difficult to approach, with the help of microscope with proper training. We can remove completely without any deficit.
\end{abstract}

Key words: Foramen magnum meningioma; Postero-lateral approach; Quadriparesis; Craniocervical, Cranial nerve palsy.

\section{INTRODUCTION}

Meningiomas are common neoplasms representing 14.3 to $19 \%$ of all intracranial tumors ${ }^{1}$. Among all the meningiomas, only 1.8 to $3.2 \%$ arises at the foramen magnum (FM) level ${ }^{2}$. Nevertheless, meningiomas are the most commonly observed FM tumors, representing $70 \%$ of all benign tumors ${ }^{3-4}$. Most of the time, these are strictly intradural. Ten percent have an extradural extension: Most are intra- and extradural, and a few may be entirely extradural ${ }^{5}$.

The lesion is often large when discovered because of their slow-growing rate, their indolent development, the difficulty of the diagnosis leading to a long interval since the first symptom, and the wide subarachnoid space at this level.

Meningiomas are slow growing, extra-axial usually benign, arise from arachnoid (not dura) usually cured if completely removed, which is not always possible. Most commonly located along falx, convexity or sphenoid bone often cause hyprostosis of adjacent bone. Frequently calcified, classic histological findings; psammoma bodies. May occur anywhere the arachnoid cells are found (between brain and skull, within ventricles and along spinal cord). Ectopic meningiomas may arise within the bone of the skull (primary intraossecous meningiomas) and other occur in the subcutaneous tissues with no attachment to the skull ${ }^{7}$. This section considers intracranial meningiomas. Usually slow growing, circumscribed (non-infiltrating), benign lesins. Histologically malignant (incidence- $1.7 \%$ of meningiomas) and/or rapidly growing varieties are also described ${ }^{8}$. May be asymptomatic. Actually arise from arachnoid cap cells (not dura). May be multiple in upto $8 \%$ of cases, this finding is more common in neurofibromatosis. Occasionally forms a diffuse sheet of tumor (meningioma en plaque) $)^{9}$. As many as $3 \%$ of autopsies on patients $>60$ years age reveals a meningioma ${ }^{9}$. Meaningomas account for $14.3-19 \%$ of primary intracranial neoplasm ${ }^{10}$. Incidence peaks at 45 years age. Female: male ratio is 1.8:1. 1.5\% occur in childhood and adolescence, usually between 10-20 years age ${ }^{11} .19-24 \%$ adolescent meningiomas occur in patients with neurofibromatosis type. 
As with any foramen magnum (FM) lesion the neurologic symtoms and signs can be very confusing and often do not initially suggest a tumor in this location. In the French Cooperative study, there were $106 \mathrm{FM}$ meningiomas, 31\% arose from the anterior lip, $56 \%$ were lateral and $13 \%$ arose from the posterior lip of the $\mathrm{FM}^{12}$. Most are intradural, but they can be extradural or a combination ${ }^{13}$.

FMMs can be classified according to their compartment of development, their dural insertion, and to their relation to the $\mathrm{VA}^{13}$. According to the compartment of development, FMMs can be subdivided in: (i) Intradural, (ii) Extradural, (iii) Intraand extradural.

Intradural meningiomas are the most commonly observed. Extradural meningiomas like at any other locations are very invasive, into the bone, the nerves and vessels sheaths, and soft tissues. The VA sheath and even its adventitia can also be infiltrated. This raises some difficulties and explains the higher incidence of incomplete removal as compared to intradural meningiomas ${ }^{14}$.

The patient may be in the sitting, ventral, or lateral position. To decrease venous bleedings, the sitting position is preferred at Lariboisière Hospital as far as there is no contraindication such as a patent foramen ovale; air embolism is prevented by hypervolemia and G-suit.

The skin is incised on the midline from the occipital protuberance down to the upper cervical region. The midline avascular plane is opened between the posterior muscles, up to the occipital protuberance and down to the spinous process of $\mathrm{C} 2$. Bone opening is performed using a drill and Kerrison rongeurs and is always limited to the lower part of the occipital bone and the posterior arch of the atlas. The dura is then incised in a T- or Yshaped fashion and retracted with stitches.

The postero-lateral approach is preferred for any intradural process located laterally and/or anteriorly to the neuraxis and for extradural lesions developed on the posterior part of the lateral FM wall ${ }^{15-16}$. For tumors extending far beyond the anterior midline, the postero-lateral approach has the advantage to allow a bilateral approach in the same stage $\mathrm{e}^{17}$.

The postero-lateral approach is a lateral extension of the midline posterior approach. The patient must be carefully positioned in the same position as during a posterior midline approach. The head must be placed in neutral position. Any flexion must be avoided because it decreases the space in front of the neuraxis and therefore may worsen the compression and the neurological condition. The vertical midline skin incision is identical, but the incision is curved laterally on the tumoral side just below the occipital protuberance toward the mastoid process. The posterior muscles are divided along the occipital crest and retracted laterally to expose the occipital bone, the posterior arch of the atlas, and the C2 lamina, if required. The exposure may be extended on a limited way on the contralateral side.

At this step, the VA running above $\mathrm{C} 1$ needs to be exposed to safely resect the $\mathrm{C} 1$ posterior arch up to the $\mathrm{C} 1$ lateral mass. The exposure of the horizontal segment of the VA V3 segment progresses from the midline of the posterior arch of the atlas laterally toward the atlas groove. The medial border of the groove is clearly marked by a step with a decrease in the height of the posterior arch. The safest way to expose the VA is to dissect strictly in the subperiosteal plane.
The posterior arch of the atlas is resected with rongeurs from the midline toward the transverse process. To obtain a decompression of the neuraxis before the tumoral resection, the posterior arch of the atlas must also be resected beyond the midline toward the controlateral side. By this way, hyperpressure induced even by gentle manipulation during resection are not transmitted to the neuraxis. The lower part of the occipital bone is drilled or resected with rongeurs laterally toward the sigmoid sinus and also beyond the midline.

\section{CASE REPORT}

A 35 years old lady had been admitted at the department of Neurosurgery, Bangabandhu Sheikh Mujib Medical University (BSMMU) with the complaints of weakness of both upper limb and lower limb since last 5 years. Weakness was progressive in nature. There was history of neck pain. No history of trauma to neck. Preoperatively higher psychic function was normal. Preoperatively tongue was deviated to left side. No history of difficulty in digglutation and no hoarseness of voice and other cranial nerves are normal. Bulk of muscle was normal. Muscle tone was increased, ankle and patellar jerks are bilaterally exaggerated. Hoffman signs are bilaterally present, planter reflex are bilaterally extensor. All other jerks are exaggerated both upper limb and lower limbs. Muscle power of right upper limb and lower limb grade I and left upper limb and lower limbs are grade II. Sensory level diminish below C3 bilaterally, cerebellar signs are normal.

MRI of cervical function revealed foramena magnum meningioma (Figure 1a \& 1b). Patient was operated at BSMMU through posterolateral approach (Figure 2a, 2b \& 2c) and total excision of tumor was done under microscope (Figure $3 a \& 3 b$ ). At post operative period, on examination, tongue was deviated to the side of lesion. Postoperative period was uneventful and muscle power of both upper and lower limb improved bilaterally. We advised for extensive physiotherapy during the postoperative period. Patient could walk without support after two months follow up and after 6 months follow up, patients had no any neurological deficit (Figure 4).

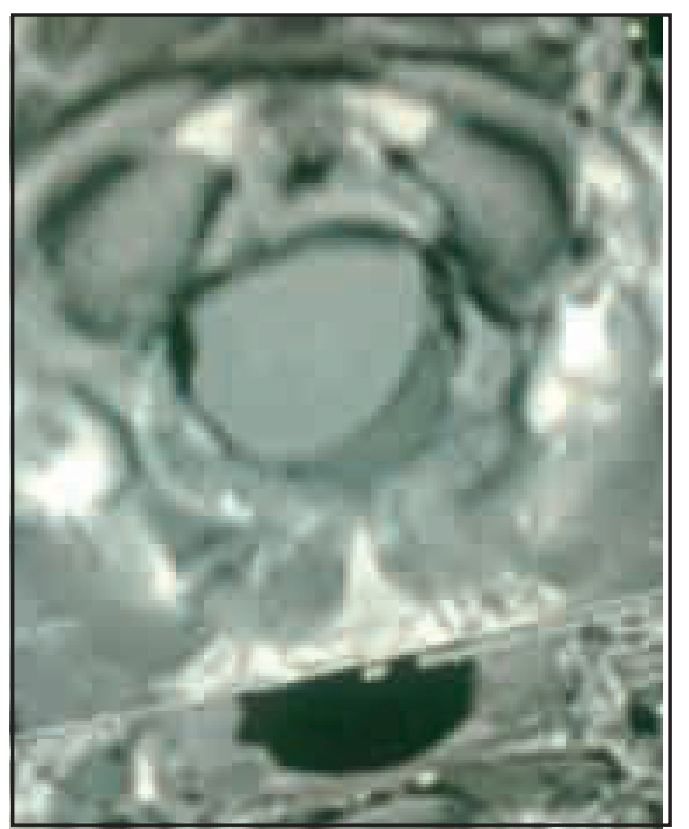

Figure 1a : Shows the MRI of cranio cervical junction foramen magnum meningioma with contrast $\&$ axial view 


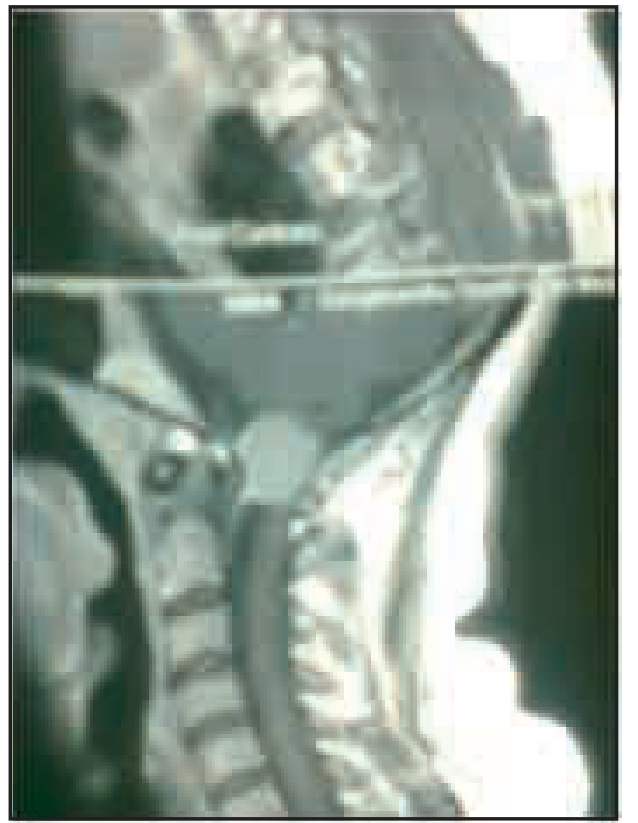

Figure 1b : Shows the MRI of CV junction with contrast foramen magnum menigioma anterior to the cord \& medula

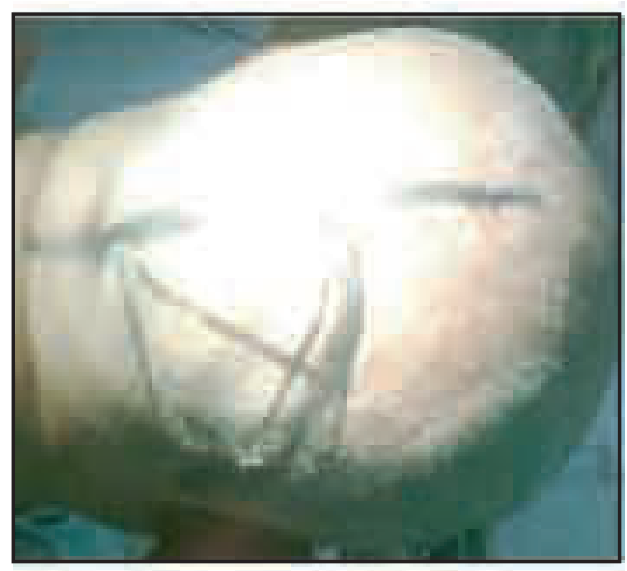

Figure 2a : Peroperative position of the patient

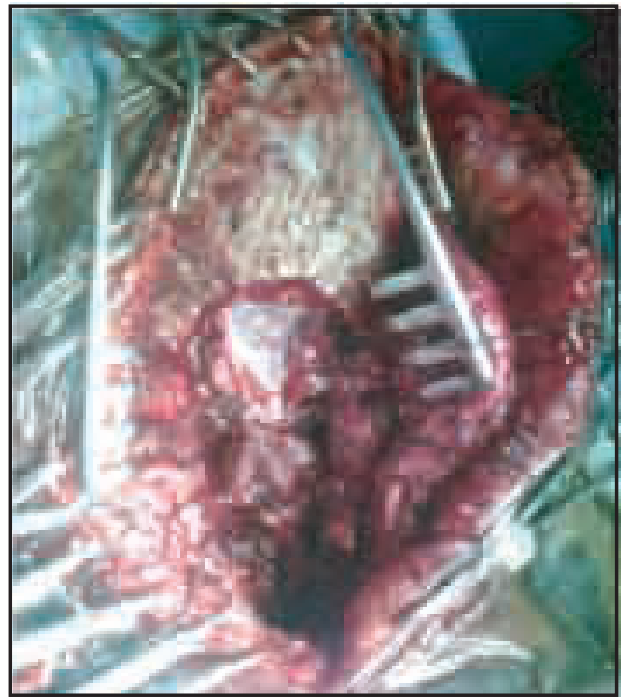

Figure $2 \mathbf{b}$ : Peroperative photo of the patient

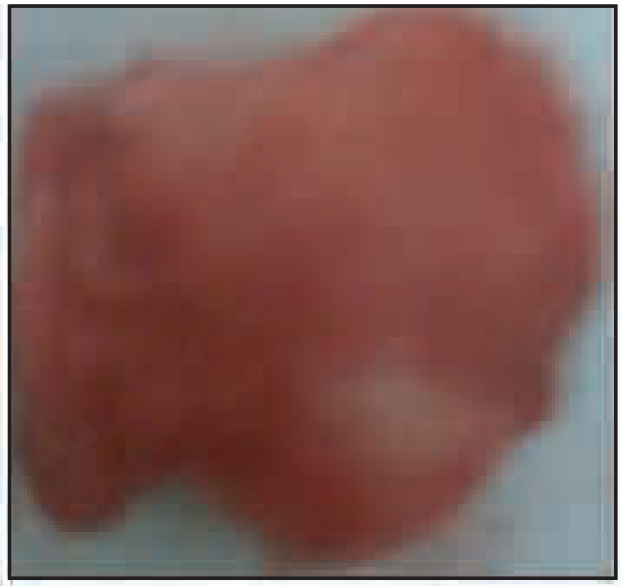

Figure 2c: Peroperative photo of the tumor

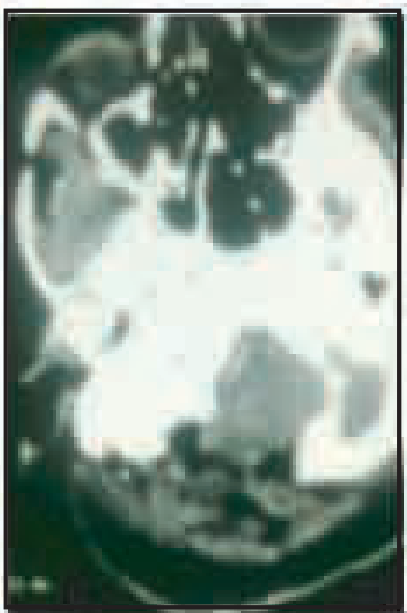

Figure 3a : Postoperative CT scan of $\mathrm{CV}$ junction, there is no residual tumor

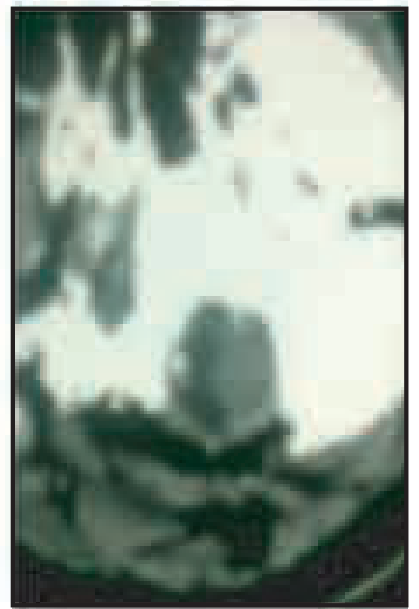

Figure $3 \mathrm{~b}$ : Postoperative CT scan of $\mathrm{CV}$ junction, there is no residual tumor

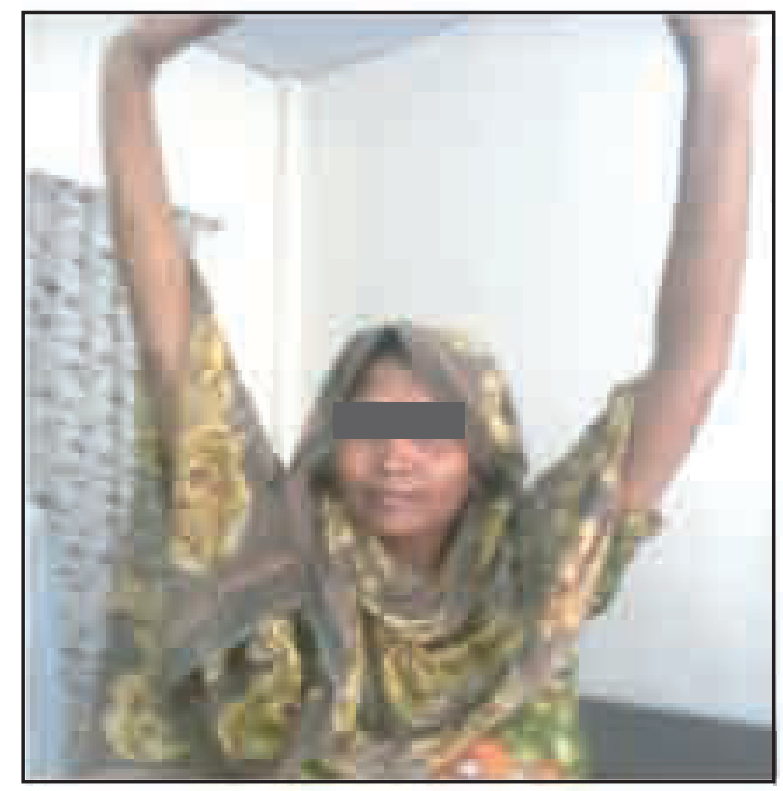

Figure 4 : Photograph of the patient after 6 months follow up without any deficit 


\section{DISCUSSION}

In the Yasargyl's review of the literature of series published before 1976 , the overall mortality rate was approximately $13 \%$ but could be as high as $45 \%$ in some series ${ }^{18}$. With the microsurgical procedure we removed the tumor completely without any harm to the patient. Over the last 20 years, the overall mortality is $6.2 \%$. The mortality rate is comprised between 0 and $25 \%$. Mortality rates higher than $10 \%$ were mainly observed in small series ${ }^{19}$.

In the Yasargil's review, a good outcome was noted in $69 \%$ and a fair and poor outcome, respectively, in 8 and $10 \%$. In series larger than ten patients published over the last 20 years, neurological improvement, stability, and worsening were noted, respectively, in $70-100,2.5-20$, and $7.5-10 \%$ of the cases. The permanent morbidity rate is comprised between 0 and $60 \%$. The permanent morbidity rate is lower through a far-lateral approach (0-17\%), either transcondylar or retrocondylar, than through an extreme-lateral transcondylar approach $(21 \%-56 \%$, considering series without recurrent tumor). We removed by posterolateral approach.

Lower cranial nerves dysfunctions are the most frequently encountered preoperative deficits. In our case preoperatively patient presented with deviation of the tongue to the left side. But after operation power of the tongue muscle was improved and the muscle power of both upper and lower limb improved. These deficits have the propensity to recover even completely postoperatively, except in cases of en plaque meningiomas or recurrent tumor ${ }^{20-21}$.

Several factors lead the surgical procedure still more difficult, then influencing negatively the morbidity rate: anterior tumor location, tumor size (smaller lesions are more difficult to resect because the surgical corridor is small), tumor invasiveness, extradural extension, VA encasement, absence of arachnoidal sheath and adherences in recurrent lesions ${ }^{22-25}$. In our case we removed the tumor completely with the help of microscope. Based on a multicentric study from 21 hopitals, George et al. reported 77,16 , and $7 \%$, respectively, of complete, subtotal, and partial removals ${ }^{26}$. Over the last 20 years, most of the studies reported complete or subtotal removal of the tumor ${ }^{27}$.
In this case we dissected the vertebral artery without any injury and without any injury to the cranial nerves. Factors limiting the resection completeness are adherences of the lesion to vital structures, VA encasement and invasiveness of the lesion. Adherences are observed during repeated surgery and explain the lower rate of complete tumor resection $(60-75 \%$ of Simpson grade 1) in surgical series in which a high rate of recurrent tumors are included ${ }^{28}$. Eventually, in recurrent tumors, some authors advocate leaving a small tumor remnant to preserve a low morbidity rate ${ }^{28}$. On the other hand, Arnautovic et al. favored radical removal of recurrent tumors with the goal of providing a relatively long and stable postoperative course, even at the price of frequent but transient morbidity induced by lower cranial nerves dysfunction ${ }^{28}$. Arnautovic et al. have also demonstrated that the rate of complete removal is higher at first surgery than when treating recurrence, advising then to be more aggressive at the first surgical presentation ${ }^{28}$. VA encasement was noted in 38 to $59 \%$ in some series ${ }^{29}$. This factor was recognized as an independent factor of incomplete removal ${ }^{30}$. The location of the meningioma, either intraextradural or extradural, reflects the tumoral invasiveness. These tumors are less favorable to be completely resected than pure intradural lesion. In the French cooperative study, the rate of complete removal of intradural, extradural, and intraextradural meningiomas was, respectively, 83,50 , and $45 \%{ }^{30}$.

In our case, we removed the tumor completely, with far lateral approach. Patient can walk without any deficit and patient had no any cranial nerve palsy and other neurological deficit.

\section{CONCLUSION}

Several surgical approaches are possible, each one with specific indications. The drilling of the FM lateral wall required during the approaches is always limited and by itself should not be at the origin of any instability. Postoperative complications can be dramatic and must be anticipated. As foramen magnum meningioma is very difficult tumor to approach with the help of microscope with skilled hand, we can remove the tumor completely without any deficit.

\section{DISCLOSURE}

All the authors declared no competing interest. 


\section{REFERENCES}

1. Wara WM, Sheline GE, Newman H, Townsend JJ, Boldrey EB. Radiation therapy of meningiomas. Am J Roentgenol Radium Ther Nucl Med. 1975; 123:453-458.

2. Arnautovic KI, Al-Mefty O, Husain M. Ventral foramen magnum meningiomas. J Neurosurg. 2000; 92(Suppl 1) :71-80

3. George B, Lot G. Anterolateral and posterolateral approaches to the foramen magnum: technical description and experience from 97 cases. Skull Base Surg. 1995;5:9-19.

4. George B, Lot G. Surgical approaches to the foramen magnum. In: Robertson JT, Coakham HB, Robertson JH (eds) Cranial base surgery. Churchill Livingstone, New York. 2000;259-279.

5. George B. Meningiomas of the foramen magnum. In: Schmidek HH (ed) Meningiomas and their surgical management. Saunders, Philadelphia. 1991;459-470.

6. Boulton MR, Cusimano MD. Foramen magnum meningiomas: concepts, classifications and nuances. Neurosurg Focus. $2003 ; 14$ (6):e10.

7. Mirimanoff RO, Dosoretz DE, Lingood RM. Mengioma: Analysis of recurrence and progression following neurosurgical resection. J Neurosurg. 1985;62:18-24.

8. Mahmood A, Caccano DV, Tomecek FJ. Atypical and malignant meningiomas: a clinic pathological review. Neurosurgery. 1993;33:955-963.

9. Sheehy JP, Crockar HA. Multiple mengiomas: A long term review. Nueurosurg. 1983;59:1-5.

10. Warra WM, Sheline GE, Newman H. Radiation therapy of meningiomas: AJR 1975;123:453-458.

11. Youmans JR. Neurological surgery, $3^{\text {rd }}$ ed. WB Saunders, Philadelphia 1990.

12. George B, Lot G, Velut S. Tumors of the foramen magnum. Neurochirgic. 1993;39:1-89.

13. George B, Lot G, Boissonnet H. Meningioma of the foramen magnum: A series of 40 cases. Surg Neurol. 1997;47:371-379.

14. Levy C, Wassef M, George B, Popot B, Compere A, Tran Ba Huy P. Meningiomes extra-crâniens. A propos de sept cas. Problemes pathogeniques, diagnostiques et therapeutiques [in French]. Ann Oto-laryngol. 1988;105:13-21.

15. George B, Lot G. Anterolateral and posterolateral approaches to the foramen magnum: technical description and experience from 97 cases. Skull Base Surg. 1995;5:9-19.

16. Pamir MN, K l c T, Ozduman K, Ture U. Experience of a single institution treating foramen magnum meningiomas. J Clin Neuroscience. 2004;11(8):863-867.

17. Samii M, Klekamp J, Carwalho G. Surgical results for meningioma of the craniocervical junction. Neurosurgery. 1996; 39:1086-1094.

18. Love JG, Thelen EP, Dodge HW. Tumors of the foramen magnum. J Int Coll Surg. 1954; 22:1-17.

19. Marin Sanabria EA, Ehara K, Tamaki N. Surgical experience with skull base approaches for foramen magnum meningioma. Neurol Med Chir (Tokyo). 2002;42:472-480.

20. Bassiouni H, Ntoukas V, Asgari S, Sandalcioglu EI, Stolke D, Seifert V. Foramen magnum meningiomas: clinical outcome after microsurgical resection via a posterolateral suboccipital retrocondylar approach. Neurosurgery. 2006; 59:1177-1187.

21. Samii M, Klekamp J, Carwalho G. Surgical results for meningioma of the craniocervical junction. Neurosurgery. 1996; 39:1086-1094.

22. George B, Lot G, Boissonnet H. Meningioma of the foramen magnum: a series of 40 cases. Surg Neurol. 1997;47:371-379.

23. Guidetti B, Spallone A. Benign extramedullary tumors of the foramen magnum. Adv Tech Stand Neurosurg. 1988; 16:83-120

24. George B, Dematons C, Cophignon J. Lateral approach to the anterior portion of the foramen magnum. Surg Neurol. 1988;29:484-490.

25. Sen CN, Sekhar LN. An extreme lateral approach to intradural lesions of the cervical spine and foramen magnum. Neurosurgery. 1990; 27:197-204

26. George B, Lot G, Velut S, Gelbert F, Mourier KL. Tumors of the foramen magnum. Neurochirurgie. 1993; 39:1-89.

27. Sharma BS, Gupta SK, Khosla VK, Mathuriya SN, Khandelwal N, Pathak A, Tewari MK, Kak VK. Midline and far lateral approaches to foramen magnum lesions. Neurol India. 1999;47:268-271.

28. Arnautovic KI, Al-Mefty O, Husain M. Ventral foramen magnum meningiomas. J Neurosurg. 2000; 92(Suppl 1):71-80.

29. Goel A, Nitta J, Kobayashi S. Supracondylar infrajugular bulb keyhole approach to anterior medullary lesions. In: Kobayashi S, Goel A, Hongo K (eds) Neurosurgery of complex tumors and vascular lesions. Churchill Livingstone, New York. 1997; $201-203$.

30. Samii M, Klekamp J, Carwalho G. Surgical results for meningioma of the craniocervical junction. Neurosurgery. 1996; 39:1086-1094. 